\title{
A new DTPw-HB/Hib combination vaccine for primary and booster vaccination of infants in Latin America
}

\author{
Miguel Tregnaghi, ${ }^{1}$ Pio López, ${ }^{2}$ Crisanta Rocha, ${ }^{3}$ Luis Rivera, ${ }^{4}$ \\ Marie-Pierre David, ${ }^{5}$ Ricardo Rüttimann, ${ }^{6}$ and Lode Schuerman ${ }^{5}$
}

Suggested citation Tregnaghi M, López P, Rocha C, Rivera L, David MP, Rüttimann R, Schuerman L. A new DTPw$\mathrm{HB} / \mathrm{Hib}$ combination vaccine for primary and booster vaccination of infants in Latin America. Rev Panam Salud Publica. 2006:19(3):179-88.

ABSTRACT Objectives. In 1998 the World Health Organization (WHO) recommended the inclusion of Haemophilus influenza type B (Hib) conjugate vaccines in infant immunization programs, whenever in accordance with national priorities. GlaxoSmithKline Biologicals has developed a new pentavalent combined diphtheria-tetanus-whole cell pertussis-hepatitis B/Hib (DTPw$\mathrm{HB} / \mathrm{Hib}$ ) vaccine containing $5 \mu \mathrm{g}$ of polyribosylribitol phosphate $(P R P)$, and we assessed the immunogenicity and reactogenicity of primary and booster vaccination of healthy children with this new vaccine compared with a reference regimen consisting of the licensed DTPw-HB (Tritanrix) and Hib (Hiberix) vaccines given as simultaneous concomitant injections.

Methods. We performed a randomized, double-blind study from September 1998 to August 1999 to establish the immunogenicity and reactogenicity of primary and booster vaccination of healthy children with the new pentavalent combined DTPw-HB/Hib vaccine given as a single injection, compared with the reference regimen.

Results. Both vaccination regimens elicited excellent immune responses, with all subjects in both groups achieving seroprotective anti-PRP antibody concentrations of $\geq 0.15 \mu \mathrm{g} / \mathrm{mL}$ one month after primary vaccination. The combined DTPw-HB/Hib vaccine was non-inferior to the licensed vaccines in terms of seroprotection/seropositivity/vaccine response rates for all antigen components. Persistence of antibodies against all study vaccine antigens up to the time of booster vaccination was comparable between groups, and a marked increase of all antibody concentrations was observed after the booster dose. Both vaccine regimens were similar in terms of their overall reactogenicity profiles.

Conclusions. Our results indicate that the new DTPw-HB/Hib pentavalent combination vaccine provides an efficient and reliable way of implementing WHO recommendations for controlling hepatitis $B$ and Hib infections on a worldwide basis.

Key words Vaccines, combined; diphtheria-tetanus-pertussis vaccine; hepatitis B vaccines; Haemophilus vaccines; Latin America.

Centro de Desarrollo de Proyectos Avanzados, Córdoba, Argentina.

2 Centro Materno Infantil Los Farallones, Cali, Colombia.

3 Hospital Infantil La Mascota, Managua, Nicaragua.

4 Maternidad Nuestra Señora de la Altagracia, Santo Domingo, Dominican Republic.
5 GlaxoSmithKline Biologicals, Rixensart, Belgium. 6 GlaxoSmithKline Biologicals, Buenos Aires, Argentina. Send correspondence to: Ricardo Rüttimann, Carlos Casares 3690, (1644) Victoria, Buenos Aires, Argentina; telephone: 54-11-4725-7995; fax: 54-114725-7997; e-mail: ricardo.w.ruttimann@gsk.com
The notion of co-administering multiple antigens in a single injection is now a widely accepted means of maximizing the efficiency and costeffectiveness of infant immunization 
programs (1). Combined vaccines also offer an opportunity to improve disease control by maximizing coverage. Hepatitis B (HB) and Haemophilus influenzae type $\mathrm{b}$ (Hib) infections continue to be endemic in many parts of the world and are still causing disease that could readily be prevented by immunization.

It has been estimated that two billion people in developing countries are now infected with hepatitis B virus and are at high risk of mortality from chronic sequelae (2). Between $70 \%$ and $90 \%$ of infants infected during the first year of life become chronic carriers (3). These children not only serve as a continuous reservoir for hepatitis B transmission, but are also themselves at risk of developing related diseases, such as cirrhosis and primary hepatocellular carcinoma, later in life $(4,5)$. For this reason the World Health Organization (WHO) recently reaffirmed its position on hepatitis $B$ vaccination, stating that "universal infant immunization is by far the most effective preventive measure against [hepatitis b virus]induced disease" (6).

$\mathrm{Hib}$ is a principal cause of pneumonia and bacterial meningitis in children, and it is associated with significant childhood morbidity and mortality around the world (3). In developing countries the incidence of $\mathrm{Hib}$ disease is higher than in the rest of the world, with infection occurring at a younger age, and with more than half of the cases occurring before 6 months of age (7). In addition, it is often difficult, if not impossible, to establish the exact cause of pneumonia cases. In at least two large field trials, Hib vaccination was shown to provide substantial protection against pneumonia in infants $(8,9)$. By preventing approximately five times as many nonbacteremic pneumonia cases as meningitis cases, the largest part of the effect of Hib vaccination might be undetectable by routine culture methods. These statistics highlight the need to provide immunization against HB and Hib disease during the first year of life. In 1998, WHO further recommended the inclusion of Hib conjugate vaccines in infant immunization programs, if ap- propriate and consistent with national capacities and priorities (10).

In 1996 the WHO set an objective for using combined vaccines such as hepatitis B viral antigen with the established diphtheria-tetanus-whole cell pertussis (DTPw) antigens (11). The Tritanrix combined DTPw-HB vaccine (GlaxoSmithKline (GSK) Biologicals, Rixensart, Belgium) has been licensed since 1996, and its immunogenicity and reactogenicity profile, when administered according to a three-dose primary course, is well-established (12-15). It has also been shown that Tritanrix can be extemporaneously mixed with the Hiberix conjugated Haemophilus influenzae vaccine (GSK Biologicals, Rixensart, Belgium) and administered as a single injection $(16,17)$.

In order to ease the implementation of the WHO recommendations, GSK Biologicals has developed a new combined DTPw-HB/Hib vaccine containing $5 \mu \mathrm{g}$ of polyribosylribitol phosphate (PRP). This study was designed to assess the immunogenicity and reactogenicity of primary and booster vaccination of healthy children with this new pentavalent combined DTPw-HB/Hib vaccine when given as a single injection, compared to a reference vaccine regimen consisting of the licensed Tritanrix and $\mathrm{Hi}$ berix vaccines given as simultaneous concomitant injections. The study was conducted in four countries of Latin America.

\section{MATERIALS AND METHODS}

\section{Study participants and study design}

The primary-vaccination study was undertaken at four centers in Latin America (Argentina (200 subjects), Colombia (300 subjects), the Dominican Republic (200 subjects), and Nicaragua (300 subjects)) from September 1998 to August 1999. The booster study was undertaken in June-July 2000 at the center in the city of Córdoba, Argentina.

One thousand healthy infants were randomized in a balanced 1:1:1:1 allocation to receive either one of three lots of the candidate combined DTPw$\mathrm{HB} / \mathrm{Hib}$ vaccine as a single injection (750 subjects total) or the licensed Tritanrix and Hiberix vaccines given as separate concomitant injections (250 subjects). Three different production lots of the combined DTPw-HB/Hib vaccine were used in a double-blind manner. Because of the two separate injections, blinding could not be maintained for the control group. The vaccines were administered according to the recommendations of the four nations' national immunization programs, at 2, 4, and 6 months of age.

In order to comply with official recommendations from the Ministry of Health of Argentina, subjects from that country (planned number $=200$ ) were invited for booster vaccination at 18 to 24 months of age, with the same vaccine that they had received during the primary course.

In all four countries, subjects were free from acute disease at the time of the first vaccination, and they were not allowed to participate in other trials or vaccination programs. The exclusion criteria were: a history of allergy to any vaccine component, prior or existing neurological disease, any previous vaccination other than with oral polio and bacillus Calmette-Guérin (BCG) vaccine, and any immune deficiency or immunosuppressive or immunoglobulin therapy.

The study was approved by the ethics committees responsible for each trial center, and was conducted in accordance with the provisions of the Declaration of Helsinki and its amendments. Good Clinical Practice guidelines were observed throughout. Written informed consent was obtained from the subjects' parents or guardians prior to entry into the study.

\section{Vaccines}

All the vaccines were manufactured by GSK Biologicals, Rixensart, Belgium. The DTPw-HB (Tritanrix) vaccine contained $\geq 30$ international units (IU) diphtheria toxoid, $\geq 60$ IU tetanus toxoid, $\geq 4$ IU Bordetella pertussis (Bp), $10 \mu \mathrm{g}$ hepatitis B surface antigen 
(HBsAg), and $0.63 \mathrm{mg}$ aluminum adjuvants (as salts). In the control group the DTPw-HB vaccine was injected concomitantly in separate injections with GSK Biologicals' licensed H. influenzae type $b$ conjugate vaccine, Hiberix, which contains $10 \mu \mathrm{g}$ of the capsular PRP polysaccharide conjugated to 20 $40 \mu \mathrm{g}$ of tetanus toxoid. In the candidate vaccine group the liquid DTPw$\mathrm{HB}$ vaccine was used to reconstitute a new lyophilized Hib-conjugate vaccine, containing $5 \mu \mathrm{g}$ of PRP, conjugated to $10-20 \mu \mathrm{g}$ of tetanus toxoid and adsorbed onto $0.06 \mathrm{mg}$ of aluminum (as salts).

\section{Serology}

Blood samples (3 $\mathrm{mL}$ ) for serology assessments were taken on entry into the study (Visit 1, at 2 months of age), prior to the third dose of primary vaccination (Post-dose 2, Visit 3, at 6 months of age), and one month after the last primary vaccination (Post-dose 3 , Visit 4, at 7 months of age). In the subset of subjects who returned for the booster study, a blood sample was also collected at the time of the booster vaccination (at 18 months of age), and one month after that (at 19 months of age).

The AUSUB radioimmunoassay (Abbott Laboratories, Abbott Park, Illinois, United States of America) was used to measure antibodies against hepatitis B surface antigen (anti-HBs), with an assay cutoff set at $10 \mathrm{mIU} / \mathrm{mL}$. Anti-tetanus and anti-diphtheria antibody concentrations were measured by ELISA, with a cutoff of $0.1 \mathrm{IU} / \mathrm{mL}$. Anti-PRP antibody concentrations were measured by enzyme-linked immunosorbent assay (ELISA), with a cutoff of $0.15 \mu \mathrm{g} / \mathrm{mL}$, and antiBordetella pertussis (anti-Bp) antibody concentrations were measured using an ELISA kit (Labsystems, Helsinki, Finland), with a cutoff of 15 ELISA units/mL $(\mathrm{EU} / \mathrm{mL})$. With the exception of anti-Bp, antibody concentrations at or above the assay cutoffs were considered to be indicative of protection against disease.

As no correlate of protection is established for Bordetella pertussis, a vac- cine response to this vaccine component was defined. For primary vaccination, taking into account the decline in maternal antibodies, a pertussis vaccine response was defined as the appearance of anti-Bp antibodies in initially seronegative subjects, or the presence of a postvaccination antibody concentration greater than or equal to the initial prevaccination concentration. A booster response against the pertussis component was defined as the appearance of antibodies in prebooster seronegative subjects, or at least a 2-fold increase in the anti-Bp antibody concentration in subjects seropositive prior to boosting.

\section{Reactogenicity}

Details of adverse events were collected on diary cards. Reactogenicity data were collected during a 4-day follow-up period after each vaccination. Solicited local symptoms included pain, redness, and swelling at the site of injection, and solicited general symptoms included drowsiness, fever (defined as axillary temperature $\geq 37.5{ }^{\circ} \mathrm{C}$ ), fussiness or irritability, and loss of appetite. Intensity of general symptoms (apart from fever) was graded on a 3-point scale, with Grade 1 corresponding to minimal discomfort and Grade 3 corresponding to interference with daily activities. All other symptoms were recorded for a period up to 30 days postvaccination, and serious adverse events (SAEs) were recorded during the entire study period.

\section{Statistical analysis}

Statistical analyses were performed for the according-to-protocol (ATP) cohorts. Subjects excluded from the ATP cohorts were identified before data analysis after a review of the individual subject data blinded to group allocation.

It was calculated that 224 evaluable subjects per treatment group would provide $90 \%$ power to reject the null hypothesis. The working hypothesis was that the percentage of subjects with anti-PRP antibody concentration $\geq 0.15 \mu \mathrm{g} / \mathrm{mL}$ one month following the immunization regimen would differ by $5 \%$ or more in at least two of the three lots. Since it was assumed that up to $10 \%$ of subjects might be unevaluable for the ATP analysis, it was necessary to enroll 250 subjects in each vaccine group. In the booster study, all subjects who had completed the primary vaccination at the center in Córdoba, Argentina (planned to be 200), were invited to participate.

Seropositivity / seroprotection / vaccine response rates and geometric mean antibody concentrations (GMCs) were calculated with $95 \%$ confidence intervals (CIs) at each blood sampling time point. For GMC calculations, samples with antibody levels below the assay cutoff were arbitrarily assigned a value corresponding to half the cutoff value of the test. The incidence of solicited symptoms was calculated with exact 95\% CIs for each type of adverse event.

The difference between groups with respect to seropositivity/seroprotection/vaccine response rates following primary vaccination was calculated with $90 \%$ CIs. The $90 \%$ CIs were computed to demonstrate noninferiority, ensuring a 5\% type I error when comparing the upper limit to the predefined non-inferiority limit (onesided test). The response following primary vaccination with the candidate DTPw-HB/Hib vaccine was considered to be non-inferior to that observed with the control vaccines if the upper limit of the $90 \%$ CI of the group difference was $<5 \%$ for anti$\mathrm{PRP} \geq 0.15 \mu \mathrm{g} / \mathrm{mL}$ and was $<10 \%$ for all other antigens.

Statistical tests were computed using SAS 6.12 software (SAS Institute Inc., Cary, North Carolina, United States) and the StatXact-3 (Cytel Inc., Cambridge, Massachusetts, United States) procedure on SAS.

\section{RESULTS}

A total of 1000 infants were enrolled in the primary-vaccination study and were randomly allocated to receive 
FIGURE 1. Number of subjects enrolled, vaccinated with either licensed diphtheria-tetanus-whole cell pertussis-hepatitis B (DTPw-HB) vaccine and Haemophilus influenzae type B (Hib) vaccine given separately or the combined DTPw-HB/Hib vaccine, and included in the according-to-protocol (ATP) analysis of reactogenicity and immunogenicity, in four countries of Latin America, 1998-1999

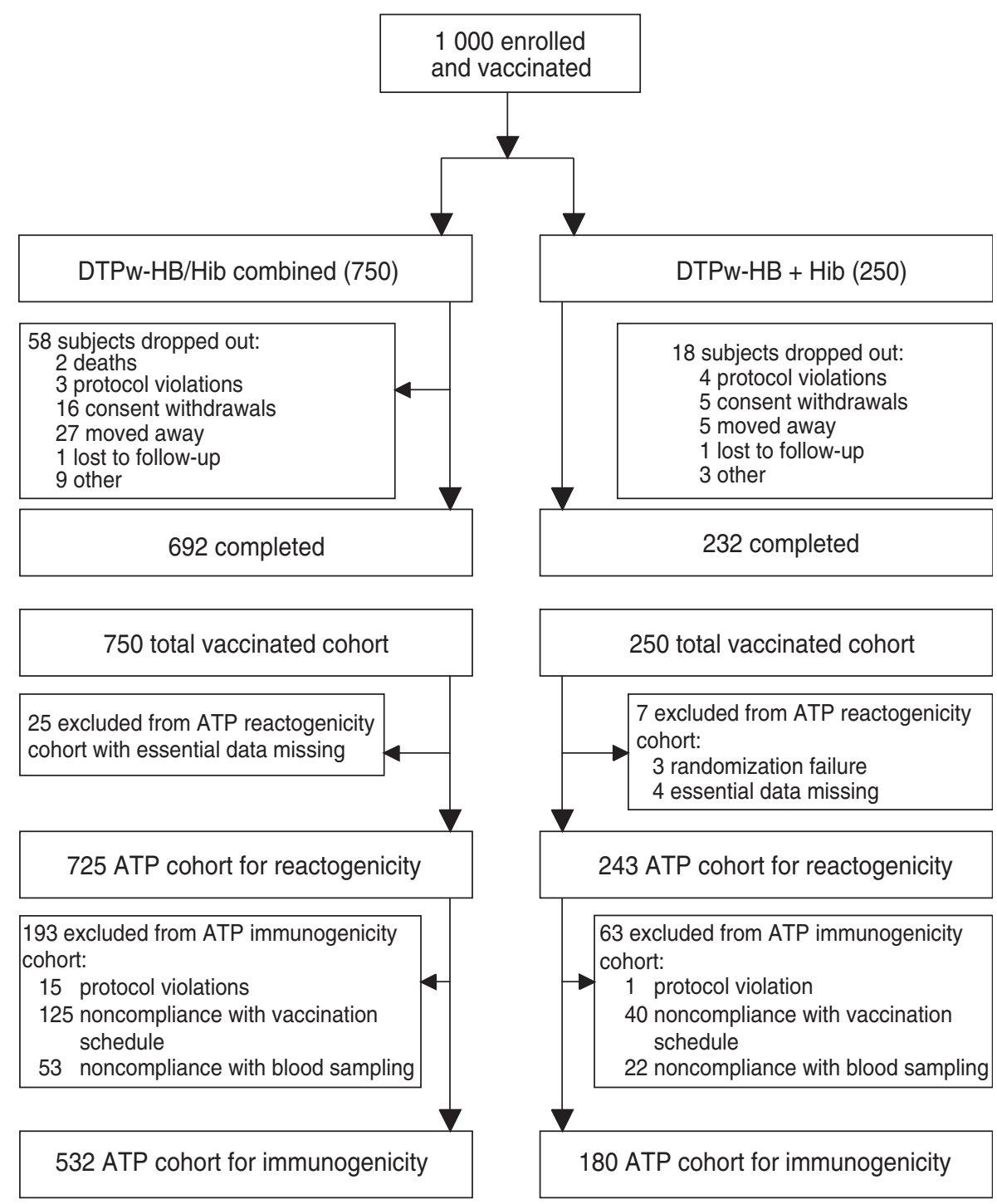

one of the two vaccine regimens. The disposition of the subjects is shown in Figure 1. Seventy-six participants did not complete the primary-vaccination study: 34 moved from the study area or were lost to follow-up, consent was withdrawn in 21 cases, 7 had protocol violations, 12 for other reasons, and 2 infants died during the study. A total of 968 subjects were included in the ATP analysis of safety (29 were ex-
A total of 143 subjects were enrolled in the booster study, out of 200 subjects enrolled for priming in Argentina. All but one subject, who moved away from the study area, completed the booster phase. Three subjects were excluded from the ATP cohort for safety (2 for randomization failure, and 1 with essential data missing), and an additional 6 subjects were excluded from the ATP cohort for immunogenicity (for failure to comply with the blood-sampling schedule).

The mean age of the total cohort at the time of first vaccination was $8.0 \pm$ 1.8 weeks, with a male:female ratio of 1:1. The mean age at the time of the booster dose was $18.0 \pm 0.73$ months, with a male:female ratio of 0.93:1.

No clinically significant differences were observed among the three different candidate DTPw-HB/Hib vaccine lots used. Therefore, we only show the results of the pooled candidatevaccine lots.

\section{Anti-PRP antibody response}

Two months after the second primary-vaccination dose, $98.7 \%$ of subjects who received DTPw-HB/Hib had anti-PRP antibody concentrations $\geq 0.15 \mu \mathrm{g} / \mathrm{mL}$, compared to $92.6 \%$ in the control group receiving the licensed DTPw-HB and Hib vaccines separately (Table 1). Following completion of the three-dose primaryvaccination course, this increased to $100 \%$ in both groups. In addition, after the third primary-vaccination dose, $99.4 \%$ of subjects who received DTPw$\mathrm{HB} / \mathrm{Hib}$ had anti-PRP antibody concentrations $\geq 1.0 \mu \mathrm{g} / \mathrm{mL}$. No significant difference between groups was observed in terms of anti-PRP antibody GMCs after primary vaccination. The anti-PRP response after primary vaccination with the new combined DTPw-HB/Hib vaccine was shown to be non-inferior to that with the licensed vaccines administered separately, since the upper limit of the $90 \%$ $\mathrm{CI}$ for the difference (control minus new combined DTPw-HB/Hib) in the percentage of subjects achieving antiPRP antibody levels $\geq 0.15 \mu \mathrm{g} / \mathrm{mL}$ was 
TABLE 1. Anti-PRP antibody responses following primary and booster vaccination with licensed DTPw-HB and Hib vaccines given separately or with combined DTPw-HB/Hib vaccine, in four countries of Latin America, 1998-1999a,b,c

\begin{tabular}{|c|c|c|c|c|c|c|c|}
\hline \multirow[b]{2}{*}{ Vaccination(s)/Timing (age in months) } & \multirow[b]{2}{*}{ No. ${ }^{d}$} & \multicolumn{2}{|c|}{ Anti-PRP $\geq 0.15 \mu \mathrm{g} / \mathrm{mL}$} & \multicolumn{2}{|c|}{ Anti-PRP $\geq 1.0 \mu \mathrm{g} / \mathrm{mL}$} & \multicolumn{2}{|c|}{ Anti-PRP } \\
\hline & & $\%{ }^{\mathrm{e}}$ & $95 \% \mathrm{Cl}$ & $\%$ & $95 \% \mathrm{Cl}^{f}$ & $\mathrm{GMC}^{\mathrm{g}}$ & $95 \% \mathrm{Cl}$ \\
\hline \multicolumn{8}{|l|}{ Separate DTPw-HB + Hib primary vaccination } \\
\hline Post-dose 2 (Month 6) & 176 & 92.6 & $87.7-96.0$ & 73.3 & $66.1-79.7$ & 3.296 & $2.488-4.367$ \\
\hline Post-dose 3 (Month 7) & 177 & 100.0 & $97.9-100.0$ & 97.2 & $93.5-99.1$ & 34.069 & $27.737-41.846$ \\
\hline \multicolumn{8}{|l|}{ Separate DTPw-HB + Hib booster } \\
\hline Prevaccination (Month 2) & 529 & 41.6 & $37.4-45.9$ & 10.0 & $7.6-12.9$ & 0.172 & $0.156-0.190$ \\
\hline Post-dose 2 (Month 6) & 521 & 98.7 & $97.3-99.5$ & 87.3 & $84.2-90.1$ & 6.186 & $5.441-7.032$ \\
\hline Post-dose 3 (Month 7) & 524 & 100.0 & $99.3-100.0$ & 99.4 & $98.3-99.9$ & 26.858 & $24.558-29.373$ \\
\hline \multicolumn{8}{|l|}{ Combined DTPw-HB/Hib booster } \\
\hline Prebooster (Month 18) & 100 & 99.0 & $94.6-100.0$ & 68.0 & $57.9-77.0$ & 2.652 & $1.921-3.661$ \\
\hline Postbooster (Month 19) & 99 & 100.0 & $96.3-100.0$ & 100.0 & $96.3-100.0$ & 87.876 & $73.215-105.474$ \\
\hline
\end{tabular}

a PRP = polyribosylribitol phosphate.

${ }^{b}$ DTPw-HB = diphtheria-tetanus-whole cell pertussis-hepatitis $B$ vaccine.

${ }^{c} \mathrm{Hib}=$ Haemophilus influenzae type B.

${ }^{\mathrm{d}}$ No. $=$ number of subjects tested.

$\mathrm{e} \%=$ percentage of subjects above the specified cutoff.

${ }^{f} \mathrm{Cl}=$ confidence interval.

g GMC = geometric mean concentration.

FIGURE 2. Anti-polyribosylribitol phosphate (anti-PRP) antibody geometric mean concentrations (GMCs) following primary and booster vaccination with licensed diphtheria-tetanus-whole cell pertussis-hepatitis B (DTPw-HB) vaccine and Haemophilus influenzae type B (Hib) vaccine given separately or with a new combined DTPw-HB/Hib vaccine, in four countries of Latin America, 1998-1999

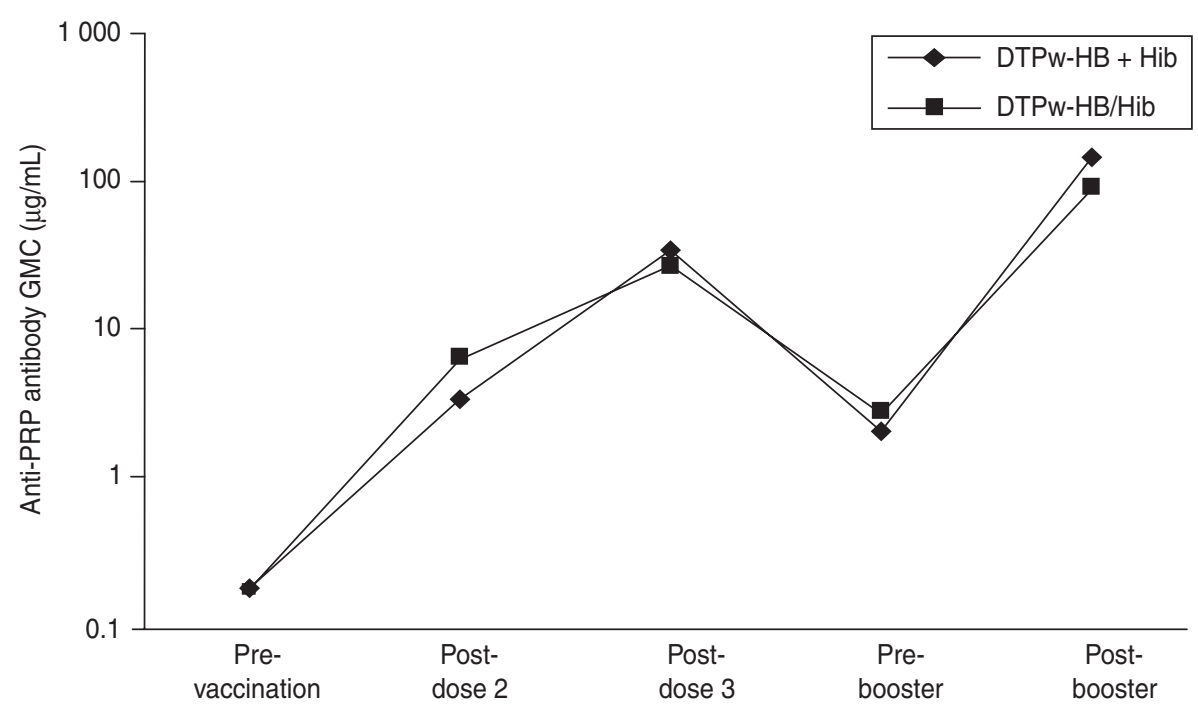

$1.1 \%$, and therefore below the predefined clinical limit of $5 \%$.

Prior to the booster dose, at approximately 18 months of age, $99.0 \%$ of the subjects in the DTPw-HB/Hib group continued to have seroprotec- tive anti-PRP antibody concentrations $\geq 0.15 \mu \mathrm{g} / \mathrm{mL}$, compared with $96.9 \%$ in the control group. A marked increase in anti-PRP antibody GMC was observed in both groups after booster vaccination (Figure 2).

\section{Response to other vaccine components}

Tables 2 and 3 present the immune response to the other vaccine antigens. The majority (> 98\%) of subjects in both groups developed seroprotective antibody concentrations against diphtheria, tetanus, and hepatitis B, and demonstrated a vaccine response against pertussis after primary vaccination (Table 2). For all the antigens, the seroprotection/vaccine response rates following primary vaccination with the candidate DTPw-HB/Hib vaccine were non-inferior to those following priming with the licensed control vaccines: The upper limit of the 90\% CIs for the differences in the percentage of subjects achieving seroprotective antibodies/vaccine response for each antigen was below the predefined clinical limit for non-inferiority (2.6\% for anti-HBs, $0.7 \%$ for antidiphtheria, $1.1 \%$ for anti-tetanus, and $1.6 \%$ for the vaccine response to $\mathrm{Bp}$ ).

After primary vaccination, anti-HBs antibody GMCs were significantly lower after DTPw-HB/Hib vaccination than after DTPw-HB + Hib vaccination (Table 3, evidenced by non-overlapping 
TABLE 2. Seroprotection rates for anti-tetanus, anti-diphtheria, and anti-HBs antibodies and vaccine response rates for anti-Bp following primary and booster vaccination with licensed DTPw-HB and Hib vaccines given separately or with combined DTPw-HB/Hib vaccine, in four countries of Latin America, 1998-1999a,b,c,d

\begin{tabular}{|c|c|c|c|c|c|c|c|c|c|c|c|c|}
\hline \multirow[b]{2}{*}{ Vaccination(s)/Timing } & \multicolumn{3}{|c|}{ Anti-tetanus $\geq 0.1 \mathrm{IU} / \mathrm{mL}^{\mathrm{e}}$} & \multicolumn{3}{|c|}{ Anti-diphtheria $\geq 0.1 \mathrm{IU} / \mathrm{mL}$} & \multicolumn{3}{|c|}{ Anti-HBs $\geq 10 \mathrm{IU} / \mathrm{mL}$} & \multicolumn{3}{|c|}{ Anti-Bp VR ${ }^{f}$} \\
\hline & No.g & $\%^{h}$ & $95 \% \mathrm{Cl}^{\mathrm{i}}$ & No. & $\%$ & $95 \% \mathrm{Cl}$ & No. & $\%$ & $95 \% \mathrm{Cl}$ & No. & $\%$ & $95 \% \mathrm{Cl}$ \\
\hline \multicolumn{13}{|c|}{$\begin{array}{l}\text { Separate DTPw-HB + Hib primary } \\
\text { vaccination }\end{array}$} \\
\hline Prevaccination & 179 & 96.6 & $92.8-98.8$ & 179 & 53.1 & $45.5-60.6$ & 174 & 4.0 & $1.6-8.1$ & & $N A^{j}$ & \\
\hline Post-dose 2 & 179 & 87.2 & 81.3-91.7 & 179 & 89.9 & 84.6-93.9 & 179 & 97.8 & 94.4-99.4 & & NA & \\
\hline Post-dose 3 & 176 & 100.0 & $97.9-100.0$ & 177 & 98.9 & $96.0-99.9$ & 177 & 99.4 & $96.9-100.0$ & 174 & 98.9 & $95.9-99.9$ \\
\hline \multicolumn{13}{|c|}{ Separate DTPw-HB + Hib booster } \\
\hline \multicolumn{13}{|c|}{$\begin{array}{l}\text { Combined DTPw-HB/Hib primary } \\
\text { vaccination }\end{array}$} \\
\hline Prevaccination & 530 & 95.5 & $93.3-97.1$ & 524 & 48.1 & $43.7-52.5$ & 518 & 5.4 & $3.6-7.7$ & & NA & \\
\hline Post-dose 2 & 529 & 99.1 & $97.8-99.7$ & 529 & 87.9 & $84.8-90.6$ & 532 & 95.1 & $92.9-96.8$ & & NA & \\
\hline Post-dose 3 & 525 & 100.0 & $99.3-100.0$ & 525 & 99.8 & $98.9-100.0$ & 524 & 99.0 & $97.8-99.7$ & 507 & 99.2 & $98.0-99.8$ \\
\hline \multicolumn{13}{|c|}{ Combined DTPw-HB/Hib booster } \\
\hline
\end{tabular}

TABLE 3. Antibody geometric mean concentration (GMC) for anti-tetanus, anti-diphtheria, anti-HBs, and anti-Bp following primary and booster vaccination with licensed DTPw-HB and Hib vaccines given separately or with combined DTPw-HB/Hib vaccine, in four countries of Latin America, 1998-1999a,b,c,d

\begin{tabular}{|c|c|c|c|c|c|c|c|c|c|c|c|c|}
\hline \multirow[b]{2}{*}{ Vaccination(s)/Timing } & \multicolumn{3}{|c|}{ Anti-tetanus } & \multicolumn{3}{|c|}{ Anti-diphtheria } & \multicolumn{3}{|c|}{ Anti-HBs } & \multicolumn{3}{|c|}{ Anti-Bp } \\
\hline & No. ${ }^{e}$ & GMC & $95 \% \mathrm{Cl}^{\dagger}$ & No. & GMC & $95 \% \mathrm{Cl}$ & No. & GMC & $95 \% \mathrm{Cl}$ & No. & GMC & $95 \% \mathrm{Cl}$ \\
\hline \multicolumn{13}{|c|}{$\begin{array}{l}\text { Separate DTPw-HB + Hib primary } \\
\text { vaccination }\end{array}$} \\
\hline Prevaccination & 179 & 1.529 & $1.294-1.807$ & 179 & 0.185 & $0.149-0.228$ & 174 & 5.9 & $5.2-6.6$ & 180 & 7.9 & $7.6-8.3$ \\
\hline Post-dose 2 & 179 & 0.352 & $0.300-0.414$ & 179 & 0.569 & $0.471-0.688$ & 179 & 502.4 & $402.3-627.3$ & 168 & 27.7 & $24.1-31.9$ \\
\hline Post-dose 3 & 176 & 2.863 & $2.452-3.343$ & 177 & 2.516 & $2.161-2.929$ & 177 & 2335.6 & $1946.7-2802.2$ & 174 & 133.7 & $119.6-149.5$ \\
\hline \multicolumn{13}{|c|}{$\begin{array}{l}\text { Combined DTPw-HB/Hib primary } \\
\text { vaccination }\end{array}$} \\
\hline Prevaccination & 530 & 1.469 & $1.323-1.631$ & 524 & 0.163 & $0.144-0.184$ & 518 & 6.0 & $5.6-6.5$ & 527 & 7.9 & $7.8-8.1$ \\
\hline Post-dose 2 & 529 & 0.739 & $0.680-0.803$ & 529 & 0.580 & $0.515-0.653$ & 532 & 402.3 & $347.4-465.8$ & 494 & 28.8 & $26.5-31.2$ \\
\hline Post-dose 3 & 525 & 4.605 & $4.263-4.973$ & 525 & 2.568 & $2.370-2.782$ & 524 & 1649.0 & $1460.1-1862.4$ & 512 & 132.2 & $124.3-140.7$ \\
\hline \multicolumn{13}{|c|}{ Combined DTPw-HB/Hib booster } \\
\hline
\end{tabular}


confidence intervals). However, there was no difference between the groups in the proportion of subjects with seroprotective anti-HBs antibodies, either immediately after priming or 12 months later, at the time of booster vaccination $(93.0 \%$ in subjects who received DTPw-HB/Hib versus $90.6 \%$ in the control group). In contrast, antitetanus antibody GMCs were significantly higher after DTPw-HB/Hib: Prior to the booster vaccination, $97.1 \%$ of subjects who received DTPw-HB/ Hib continued to have seroprotective anti-tetanus antibodies, compared to $78.1 \%$ of subjects who received the control vaccines.

One month after the booster vaccination, marked increases in GMCs were observed for antibodies against each of the vaccine antigens (Table 3 ). All subjects who received DTPw-HB/ Hib had seroprotective antibodies against tetanus and diphtheria and demonstrated a booster response to pertussis, and $99 \%$ were seroprotected against hepatitis B. There was no evidence to suggest a difference between the groups in terms of postbooster antibody GMCs for any of the vaccine antigens.

\section{Reactogenicity}

The occurrence of local and general symptoms after primary and booster vaccination is shown in Figure 3. The incidence and intensity of symptoms were comparable in both vaccine groups, as demonstrated by overlap of 95\% CIs.

Pain at the injection site was the most commonly reported solicited local symptom after both primary and booster vaccination, and irritability/ fussiness was the most frequently reported solicited general symptom. The incidence of local symptoms was higher following the booster dose than after the primary course.

During the primary-vaccination course, unsolicited symptoms considered by the investigators to be probably related to vaccination occurred after $0.8 \%$ of the licensed vaccine doses and after $1.2 \%$ of the combined DTPw-
$\mathrm{HB} / \mathrm{Hib}$ vaccine doses. These were application site reactions, childhood infections, or gastrointestinal symptoms.

Fourteen SAEs were reported during the primary-vaccination study; one was determined to be probably vaccinerelated. This infant received DTPw$\mathrm{HB} / \mathrm{Hib}$ and developed cellulitis at the injection site after Dose 2 , which required treatment with cephalexin. The third dose of vaccine was given without any recurrence of infection. There were two deaths during the study. One was due to diarrhea, vomiting, and convulsions; it occurred 52 days after the infant received the first combination vaccine dose. The other death, due to pneumonia and septicemia, happened 8 days after the second DTPw$\mathrm{HB} / \mathrm{Hib}$ dose. The investigators did not consider either death to be related to vaccination. The remaining 11 SAEs were mainly due to infectious diseases such as otitis, respiratory tract infections, meningitis, or diarrhea.

Two SAEs were reported during the booster study. One event (cellulitis that developed at the DTPw-HB injection site following the booster dose of the licensed vaccine) was considered by the investigators to be probably vaccine-related. The event resolved within 10 days.

\section{DISCUSSION}

The results of this study demonstrate a good immunogenicity and reactogenicity profile for the new combined DTPw-HB/Hib vaccine containing $5 \mu \mathrm{g}$ PRP per dose. Statistical comparisons based on the results following primary vaccination showed that, in terms of the antibody response to the PRP antigen, the combined $\mathrm{DTPw}-\mathrm{HB} / \mathrm{Hib}$ vaccine was clinically non-inferior to the licensed DTPw-HB and Hib vaccines. Persistence of antiPRP antibodies until the age of booster vaccination was within the same range in both groups, and the booster dose induced anti-PRP antibody concentrations $\geq 1 \mu \mathrm{g} / \mathrm{mL}$ in $100 \%$ of vaccinees. The substantial increases in anti-PRP antibody levels following the booster dose are indicative of effective prim- ing and induction of immune memory, regardless of the amount of PRP administered in the primary series.

This study also demonstrated noninferiority of the candidate DTPw$\mathrm{HB} / \mathrm{Hib}$ vaccine, compared to the licensed-vaccines control group, in terms of the antibody responses to the other vaccine antigens. Although the anti-HBs antibody GMCs after primary vaccination were significantly lower with DTPw-HB/Hib than with DTPw-HB + Hib, the clinical relevance of this observation is likely to be limited, given the high anti-HBs seroprotection rates observed following priming and maintained until the time of booster vaccination. The observed prebooster antibody persistence following priming with the combined candidate DTPw-HB/Hib vaccine was at least as good as the observed prebooster antibody persistence following primary vaccination with the licensed vaccines administered separately. Marked increases in antibody GMCs for all vaccine antigens were found in both groups.

There was no difference between the groups in terms of the tolerability of the combined DTPw-HB/Hib vaccine compared to the separate administration of the licensed vaccines. In both groups, local symptoms were reported with a higher frequency with the booster dose than with the primary course. Such an increase has previously been seen after booster vaccination with DTPw, as well as with diphtheria-tetanus-acellular pertussis combination vaccines (18-21).

This study has some limitations. It was not possible to make the study double-blind, due to the different number of injections in the control group. Therefore, there is a possibility of bias in the reporting of reactogenicity. Subjects were recruited from four countries within Latin America, and it cannot be excluded that the perception of reactogenicity of the vaccines may have varied from country to country. Finally, the use of the new DTPw-HB/ Hib vaccine in "field" conditions, for example including use in immunocompromised subjects, was not assessed in this trial. However, since the 
FIGURE 3. Incidence of any and of Grade 3 solicited local and general symptoms following primary and booster vaccination with licensed diphtheria-tetanus-whole cell pertussis-hepatitis B (DTPw-HB) vaccine and Haemophilus influenzae type B (Hib) vaccine given separately or with a new combined DTPw-HB/Hib vaccine, with $95 \%$ confidence intervals, in four countries of Latin America, 1998-1999a

Pain

$\%$ of doses

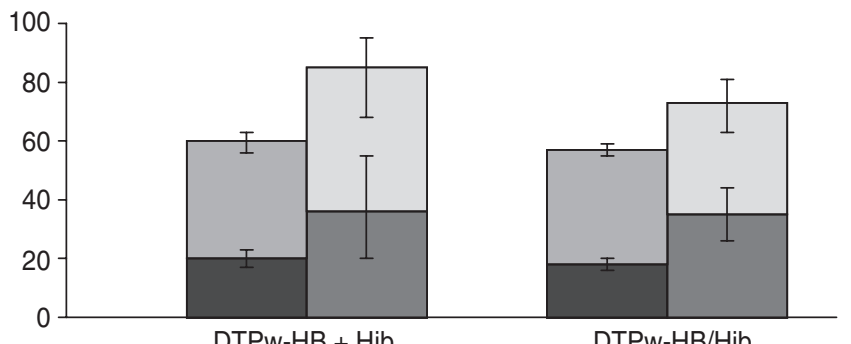

DTPw-HB + Hib

Drowsiness

$\%$ of doses

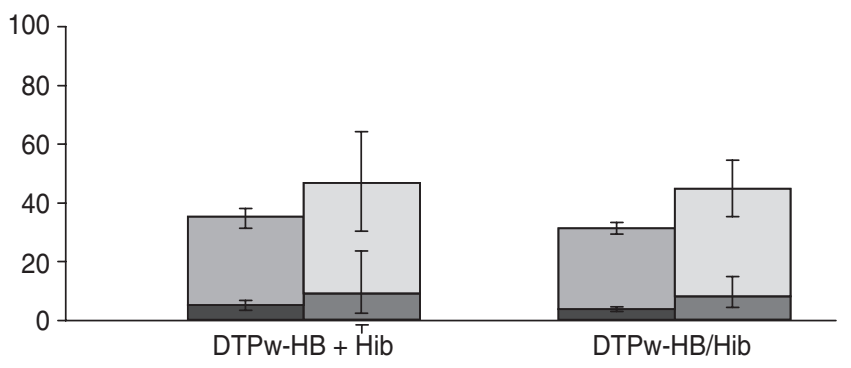

Swelling

$\%$ of doses

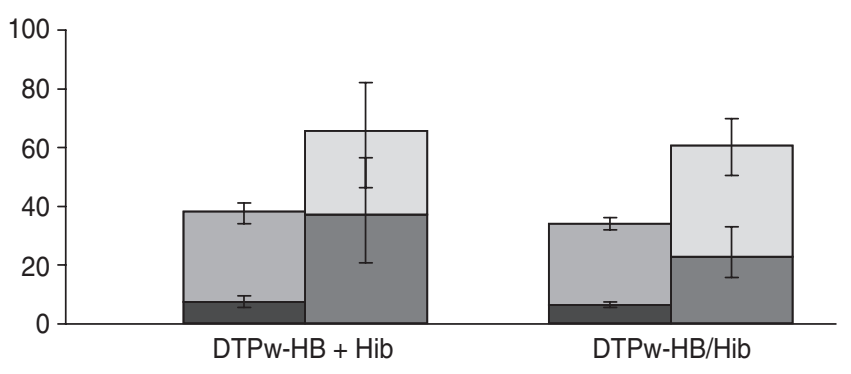

Fever

$\%$ of doses

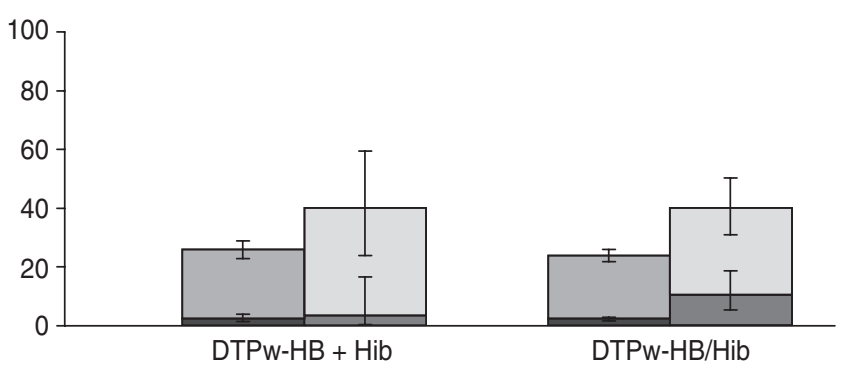

Redness

$\%$ of doses

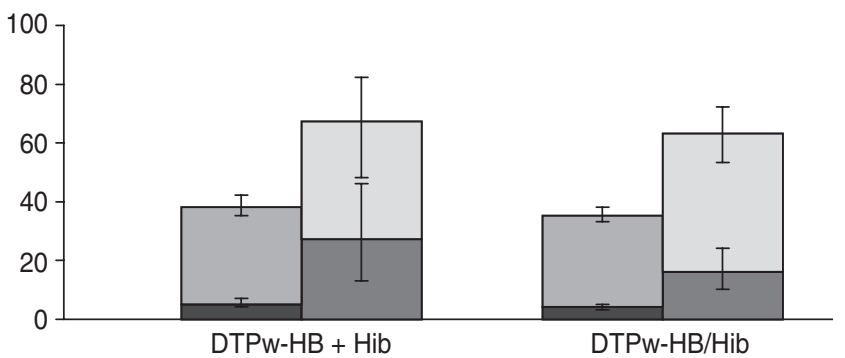

Irritability/fussiness

$\%$ of doses

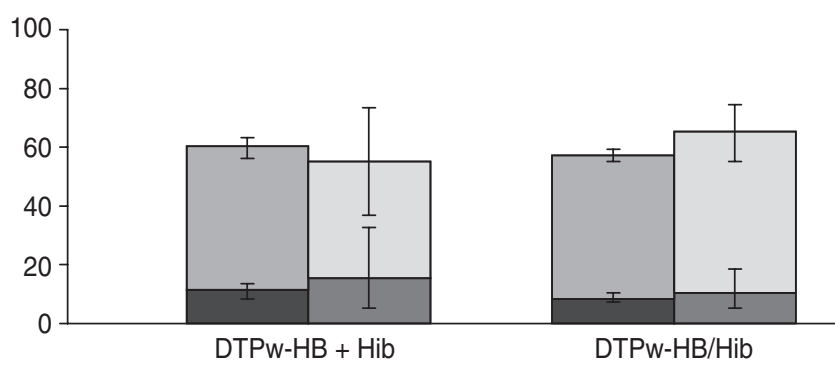

Loss of appetite

$\%$ of doses

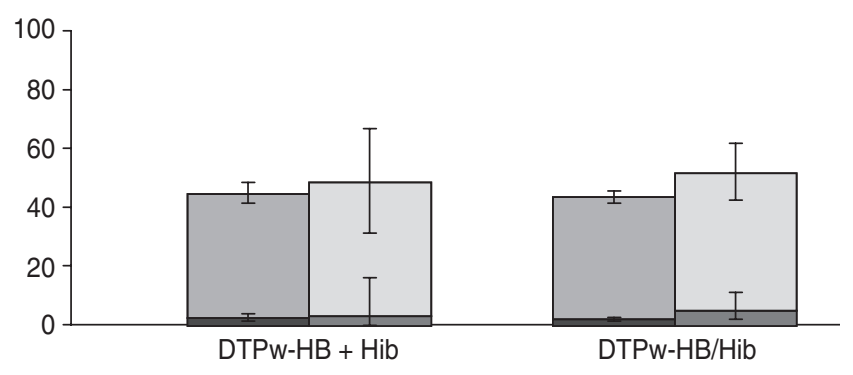

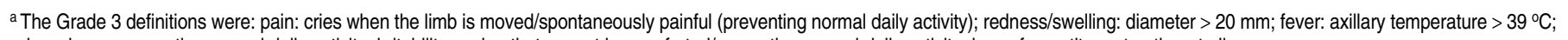
drowsiness: preventing normal daily activity; irritability: crying that cannot be comforted/preventing normal daily activity; loss of appetite: not eating at all. 
$\mathrm{DTPw}-\mathrm{HB} / \mathrm{Hib}$ vaccine is a combination of well-known and commonly used antigens, it is unlikely that the performance of the new vaccine would be different from that of the currently licensed products.

Fractional doses of conjugate $\mathrm{Hib}$ vaccines have been shown to be as immunogenic as current licensed vaccines (22-27), and the antibodies appeared to have functional characteristics (antibody avidity) that were at least as good as those induced by licensed products $(28,29)$.

This study demonstrates the immunogenicity and tolerability of the new combined pentavalent DTPw$\mathrm{HB} / \mathrm{Hib}$ vaccine. This vaccine will pro- vide protection against five major childhood pathogens and will ease the implementation of global pediatric immunization programs, with a minimum of injections and a potentially improved immunization coverage.

Acknowledgements. The authors would like to acknowledge Ruby Terracciano and Julia Donnelly for their technical assistance. This study was supported by a grant from GSK Biologicals, Rixensart, Belgium.

Note on conflict of interest. The Pan American Health Organization (PAHO) has purchased vaccines from GlaxoSmithKline, and PAHO has also received contributions from GlaxoSmithKline. While the Revista Panamericana de Salud Pública/Pan American Journal of Public Health is affiliated with PAHO, the Revista/Journal is an independent scientific publication whose articles do not necessarily reflect the opinions or official positions of PAHO on specific issues. The mention of particular companies or of certain manufacturers' products in the Revista/Journal does not imply that they are endorsed or recommended by PAHO in preference to other ones of a similar nature. As with all other research articles published in the Revista/Journal, this article went through the regular process of peer review by outside experts.

\section{REFERENCES}

1. André FE. Development and clinical application of new polyvalent combined paediatric vaccines. Vaccine. 1999;17:1620-7.

2. World Health Organization. Hepatitis B. Geneva: WHO; 2000. (Fact Sheet WHO/204).

3. Peltola $\mathrm{H}$. Worldwide Haemophilus influenzae type $b$ disease at the beginning of the 21st century: global analysis of the disease burden 25 years after the use of the polysaccharide vaccine and a decade after the advent of conjugates. Clin Microbiol Rev. 2000;13(2):302-17.

4. Yeoh EK. Hepatitis B virus infection in children Vaccine. 1990;8:S29-30.

5. Kane MA. Status of hepatitis B immunization programmes in 1998. Vaccine. 1998;16(suppl): S104-8.

6. World Health Organization. Hepatitis B vaccines. Wkly Epidemiol Rec. 2004;79:253-64.

7. Bijlmer HA. Epidemiology of Haemophilus influenzae invasive disease in developing countries and intervention strategies. In: Ellis RW, Granoff DM, eds. Development and clinical uses of Haemophilus b conjugate vaccines. New York: Marcel Dekker; 1994. Pp. 247-64.

8. Mulholland K, Adegbola R. The Gambian Haemophilus influenzae type $\mathrm{b}$ vaccine trial: what does it tell us about the burden of Haemophilus influenzae type $\mathrm{b}$ disease? Pediatr Infect Dis J. 1998;17:S123-5.

9. Levine O, Lagos R, Muñoz A, Villaroel J, Alvarez AM, Abrego P, et al. Defining the burden of pneumonia in children preventable by vaccination against Haemophilus influenzae type b. Pediatr Infect Dis J. 1999;18:1060-4.

10. World Health Organization, Global Programme for Vaccines and Immunization. The WHO position paper on Haemophilus influenzae type $\mathrm{b}$ conjugate vaccines. Wkly Epidemiol Rec. 1998;73:64-8.

11. World Health Organization. The children's vaccine initiative and the global programme for vaccines and immunization: recommendations from the special advisory group of experts. Part 1. Wkly Epidemiol Rec. 1996;71: 261-6.

12. Poovorowan $Y$, Theamboonlers A, Sanpavat S, Chongsrisawat V, Willems P, Safary A. Comparison study of combined DTPw-HB vaccines and separate administration of DTPw and $\mathrm{HB}$ vaccines in Thai children. Asian Pac J Allergy Immunol. 1999;17(2):113-20.

13. Usonis V, Bakasenas V, Taylor D, Vandepapeliére $\mathrm{P}$. Immunogenicity and reactogenicity of a combined DTPw-hepatitis B vaccine in Lithuanian infants. Eur J Pediatr. 1996;155: 189-93.

14. Aristegui J, Garrote E, González A, Arrate JP, Perez A, Vandepapeliere P. Immune response to a combined hepatitis $B$, diphtheria, tetanus and whole-cell pertussis vaccine administered to infants at 2, 4, and 6 months of age. Vaccine. 1997;15:7-9.

15. Diez-Delgado J, Dal-Ré R, Llorente M, González A, López J. Hepatitis B component does not interfere with the immune response to diphtheria, tetanus and whole-cell Bordetella pertussis components of a quadrivalent $(\mathrm{DTPw}-\mathrm{HB})$ vaccine: a controlled trial in healthy infants. Vaccine. 1997;15:1418-22.

16. Win KM, Aye M, Htay-Htay H, Safary A, Bock H. Comparison of separate and mixed administration of DTPw-HBV and Hib vaccines: immunogenicity and reactogenicity profiles. Int J Infect Dis. 1997;2:79-84.

17. Bravo L, Carlos J, Gatchalian S, Borja-Tabora $C$, Bibera G, Willems P, et al. The new DTPw$\mathrm{HBV}-\mathrm{Hib}$ combination vaccine can be used at the WHO schedule with a monovalent dose of hepatitis B vaccine at birth. Southeast Asian J Trop Med Public Health. 1998;29:772-8.

18. Pichichero ME, Deloria MA, Rennels MB, Anderson EL, Edwards KM, Decker MD, et al. A safety and immunogenicity comparison of 12 acellular pertussis vaccines and one wholecell pertussis vaccine given as a fourth dose in 15- to 20-month-old children. Pediatrics. 1997; 100:772-88.

19. Schmitt HK, Beutel K, Schuind A, Knuf M, Wagner S, Muschenborn S, et al. Reactogenicity and immunogenicity of a booster dose of a combined diphtheria, tetanus, and tricomponent acellular pertussis vaccine at fourteen months to twenty-eight months of age. J Pediatr. 1997;130:616-23.

20. Tozzi A, Anemona A, Stefanelli P, Salmaso S, Atti ML, Mastrantonio P, et al. Reactogenicity and immunogenicity at preschool age of a booster dose of two three-component diphtheria-tetanus-acellular pertussis vaccines in children primed in infancy with acellular vaccines. Pediatrics. 2001;107:E25.

21. Halperin SA, Eastwood BJ, Barreto L, Friesen B, Medd L, Meekison W, et al. Adverse reactions and antibody response to four doses of acellular or whole cell pertussis vaccine combined with diphtheria and tetanus toxoids in the first 19 months of life. Vaccine. 1996;14: 767-72.

22. Mendelman PM, Feeley L, Bird S, Staub T, Matthews H, Del Beccaro MA, et al. Immunogenicity and safety of Haemophilus influenzae type $\mathrm{b}$ polysaccharide-Neisseria meningitidis conjugate vaccine in 7.5 micrograms liquid formulation: a comparison of three lots with the 15.0 micrograms lyophilized formulation. Study Group for 7.5 micrograms Liquid PedvaxHIB. Vaccine. 1997;15:775-81.

23. Lagos R, Valenzuela MT, Levine OS, Losonsky GA, Erazo A, Wasserman SS, et al. Economisation of vaccination against Haemophilus influenzae type $\mathrm{b}$ : a randomized trial of immunogenicity of fractional-dose and twodose regimens. Lancet. 1998;351:1472-6.

24. Nicol M, Huebner R, Mothupi R, Kayhty H, Mbelle N, Khomo E. Haemophilus influenzae 
type $\mathrm{b}$ conjugate vaccine diluted tenfold in diphtheria-tetanus-whole cell pertussis vaccine: a randomized trial. Pediatr Infect Dis J. 2002;21:138-41.

25. Fernández J, Balter S, Feris J, Gómez E, Garib Z, Castellanos PL, et al. Randomized trial of the immunogenicity of fractional dose regimens of PRP-T Haemophilus influenzae type $\mathrm{b}$ conjugate vaccine. Am J Trop Med Hyg. 2000; 62:485-90.

26. Anderson EL, Frey S, Geldmacher K, Radley D, Lee A, Donnelly J, et al. Safety, tolerability and immunogenicity of low dose Haemophilus influenzae type b conjugated to the outer mem- brane protein complex of Neisseria meningitidis group B. Pediatr Infect Dis J. 2002;21:350-2.

27. Huebner RE, Nicol M, Mothupi R, Kayhty H, Mbelle N, Khomo E, et al. Dose response of $\mathrm{CRM}_{197}$ and tetanus toxoid-conjugated Haemophilus influenzae type $\mathrm{b}$ vaccines. Vaccine. 2004;23:802-6.

28. Romero-Steiner S, Fernandez J, Biltoft $\mathrm{C}$, Wohl ME, Sanchez J, Feris J, et al. Functional antibody activity elicited by fractional doses of Haemophilus influenzae type $\mathrm{b}$ conjugate vaccine (polyribosylribitol phosphate-tetanus toxoid conjugate). Clin Diagn Lab Immunol. 2001;8:1115-9.
29. Campbell JD, Lagos R, Levine MM, Losonsky GA. Standard and alternative regimens of Haemophilus influenzae type $\mathrm{b}$ conjugate vaccine (polyribosylribitol phosphate-tetanus toxoid conjugate vaccine) elicit comparable antibody avidities in infants. Pediatr Infect Dis J. 2002;21:822-6.

Manuscript received 22 February 2005. Revised manuscript accepted for publication 1 September 2005.
RESUMEN

Nueva vacuna combinada DTPw-HB/Hib para la vacunación primaria y de refuerzo de menores de un año en América Latina
Objetivos. En 1998, la Organización Mundial de la Salud (OMS) recomendó que se incluyeran vacunas conjugadas contra Haemophilus influenzae tipo B (Hib) en los programas de vacunación de niños menores de un año, siempre que ello estuviera en consonancia con las prioridades nacionales. La compañía GlaxoSmithKline Biologicals ha creado una nueva vacuna pentavalente que es una combinación de la vacuna contra la difteria (D), el tétanos (T) y la tos ferina (P) (con antígeno tosferínico a base de células completas) y las vacunas contra la hepatitis B (HB) y contra Haemophilus influenzae tipo B (Hib) (DTPw-HB/Hib), con un total de $5 \mu \mathrm{g}$ de fosfato de polirribosilrribitol (FPR). Hemos evaluado la inmunogenia y reactogenia observadas al aplicarse las dosis primaria y de refuerzo de esta nueva vacuna a niños sanos y las hemos comparado con las observadas al aplicar un régimen de referencia a base de las vacunas autorizadas DTPw-HB (Tritanrix) y antiHib (Hiberix) en forma de inyecciones simultáneas.

Métodos. Llevamos a cabo un estudio aleatorizado y con doble enmascaramiento de septiembre de 1998 a agosto de 1999 para establecer la inmunogenia y reactogenia observadas al administrarles a niños sanos la nueva vacuna combinada pentavalente (DTPw-HB/Hib) en una sola inyección, y compararlas con las observadas con el régimen de referencia.

Resultados. Se obtuvieron excelentes respuestas inmunitarias con ambos regímenes. Todos los niños vacunados en ambos grupos alcanzaron concentraciones séricas protectoras de anticuerpos antiFPR $\geq 0,15 \mu \mathrm{g}$ un mes después de recibir la dosis primaria. La vacuna combinada DTPw-HB/Hib no dio resultados inferiores a los obtenidos con las vacunas autorizadas en términos de los porcentajes de seroprotección, seropositividad y respuesta frente a todos los componentes antigénicos de la vacuna. La persistencia de anticuerpos contra todos los antígenos contenidos en ella hasta el momento en que se administró la dosis de refuerzo fue parecida en ambos grupos, y se observó un marcado aumento de las concentraciones de todos los anticuerpos después del refuerzo. La reactogenia general observada con ambos regímenes de vacunación fue parecida.

Conclusiones. Nuestros resultados indican que la nueva vacuna combinada pentavalente $\mathrm{DTPw}-\mathrm{HB} / \mathrm{Hib}$ ofrece una manera eficiente y confiable de poner en práctica las recomendaciones de la OMS para el control de la hepatitis B y de las infecciones por Hib en el mundo entero.

Palabras clave Vacunas combinadas, vacuna difteria-tétano-pertussis, vacunas contra hepatitis B, vacunas contra Haemophilus; América Latina. 